\title{
Characteristics of the Heart of School-Age Children in a Schistosomiasis Endemic Area in Senegal
}

\author{
Simon Antoine Sarr ${ }^{*}$, Roger Camara1, Fassi-Fehri Hicham1, Cheikh-Binetou Fall2, \\ Ibrahima Sory2 Sylla', Fatou Aw' ${ }^{1}$, Malick Bodian', Mouhammadou Bamba Ndiaye1, \\ Alassane Mbaye ${ }^{3}$, Adama Kane ${ }^{1}$, Babacar Faye ${ }^{2}$, Maboury Diao' , Abdoul Kane ${ }^{4}$, \\ Serigne Abdou Ba ${ }^{1}$
}

${ }^{1}$ Cardiology Unit, Aristide Le Dantec Teaching Hospital, Dakar, Senegal

${ }^{2}$ Parasitology Laboratory, Cheikh Anta Diop University, Dakar, Senegal

${ }^{3}$ Cardiology Unit, Grand Yoff General Hospital, Dakar, Senegal

${ }^{4}$ Cheikh Anta Diop University, Dakar, Senegal

Email: *sarrsimantoine@yahoo.fr

How to cite this paper: Sarr, S.A., Camara, R., Hicham, F.-F., Fall, C.-B., Sylla, I.S., Aw, F., Bodian, M., Ndiaye, M.B., Mbaye, A., Kane, A., Faye, B., Diao, M., Kane, A. and Ba, S.A. (2018) Characteristics of the Heart of School-Age Children in a Schistosomiasis Endemic Area in Senegal. World Journal of Cardiovascular Diseases, 8, 441-451. https://doi.org/10.4236/wjcd.2018.89043

Received: August 5, 2018

Accepted: September 7, 2018

Published: September 10, 2018

Copyright $\odot 2018$ by authors and Scientific Research Publishing Inc. This work is licensed under the Creative Commons Attribution International License (CC BY 4.0).

http://creativecommons.org/licenses/by/4.0/

(c) $\underset{\mathrm{EY}}{\mathrm{B}}$ Open Access

\begin{abstract}
Introduction: In Senegal, surveys have revealed areas of high endemicity of Schistosomiasis including the town of Richard Toll. We undertook this study to determine the echocardiocardiographic characteristics of school-age children in endemic bilharziasis. Methodology: We performed a descriptive cross-sectional study in Richard Toll and Dakar in school-age children. Results: A total of 250 children were included. There was male predominance, age between 4 and 16 (10 years old \pm 2.77 ). Hematuria was reported in $69.6 \%$ of cases in endemic areas. Positive testing for Schistoma hæmatobium was found exclusively in Richard-Toll at 33.5\%. The diastolic, systolic, basal and median left ventricle dimensions were larger in Richard Toll's population compared to Dakar. It was the same for the right chambers dimensions. The average pulmonary systolic arterial pressure was greater in Richard-Toll: $26.38 \pm 3.16 \mathrm{mmHg}$ versus $21.82 \pm 1.73 \mathrm{mmHg}$ in Dakar $(\mathrm{p}<0.001)$. There was a correletion between pulmonary systolic artérial pressure and presence of hematuria, anemia and parasitological positivity. Conclusion: The heart of the school-aged child in endemic area is characterized by larger cavitary dimensions.
\end{abstract}

\section{Keywords}

Schistoma hæmatobium, Hematuria, Cardiac Chambers Dilatation 


\section{Introduction}

Bilharziasis or Schistosomiasis is a parasitosis caused by a helminth of the genus Schistosoma transmitted to humans by transcutaneous passage during a bath in fresh water. It is a neglected tropical disease and the second most common parasitic disease in the world [1] [2]. It is said to be responsible for more than 200,000 deaths a year worldwide. Bilharzia is endemic in five regions: Africa, America, Southeast Asia, the Eastern Mediterranean and the Western Pacific. This parasitosis is a major public health problem in Africa, the most affected continent with 43 endemic countries [1]. In Senegal, surveys revealed that 12 of 14 regions and 59 out of 76 districts were endemic for schistosomiasis. The northern area of Senegal, on the banks of the River, reflects this state of affairs more. In fact, in the town of Richard-Toll, the infestation with Schistosoma hæmatobium is $87 \%$ [3].

Clinical manifestations as well as complications depend on the species but also on the stage and duration of infestation [4]. The most common cardiovascular complication of bilharziasis is pulmonary arterial hypertension. Moreover, this condition is described as the most provider of PHT in the world [5]. The pathophysiology of this hypertension is poorly understood. In addition, some forms of endomyocardial fibrosis, myocarditis and pericarditis have been described [6] [7] [8]. Also, urinary schistosomiasis, a source of hematuria, could have a cardiovascular impact through anemia. Children, especially those of school age, pay a heavy price in endemic areas [1]. Although prevalence studies have established the mapping of schistosomiasis in Senegal, no work has been done on cardiac complications.

We undertook this study to determine the echocardiocardiographic characteristics of school-age children in endemic bilharziasis.

The specific objectives were as follows:

- Describe the pulmonary artery and cardiac chambers dimensions;

- To measure pulmonary artery pressure;

- To appreciate these echocardiographic data by comparing them with data from a population not living in an endemic area.

\section{Methodology}

We conducted a descriptive cross-sectional survey.

Study Framework: Our study took place at Richard-Toll in the regions of Saint-Louis and Dakar, about $330 \mathrm{~km}$ apart. The choice of Richard-Toll (Figure 1 ) is justified by the very high prevalence of schistosome infestation in relation to a river network constituted by the Senegal River [9]. Dakar, the capital of Senegal is free from any infestation.

Period: The project took place in the field in June and July 2017. Data processing and report writing continued until October of the same year.

Study Population: Our study was conducted in daaras and schools in Dakar and Richard-Toll. As a reminder, the term "daara", of Arabic origin passed 


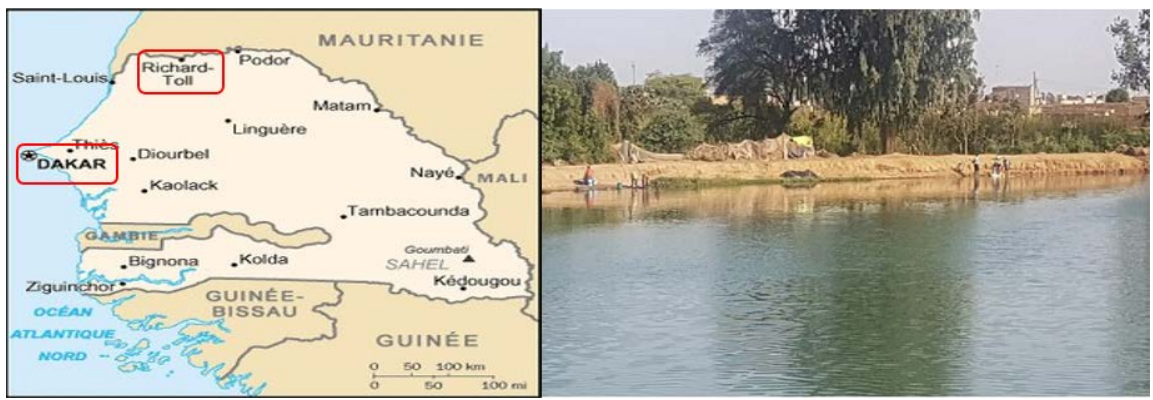

Figure 1. Location of Richard Toll on the map of Senegal (left); image illustrating activities in the river (laundry, bathing).

Wolof, first designates a court, a villa, a house, then more specifically a center of religious education, or any place where the Koran is taught [10].

To Richard Toll, it is:

- Daara "BA", It includes exclusively boys, about thirty years old between 4 and 14 years old.

- Daara "SOW", it includes exclusively boys, about fifty children, aged 6 to 16 years.

- Richard-Toll School: This elementary school of the public teacher has classes from $1^{\text {st }}$ to $5^{\text {th }}$ grade. About 250 students, boys and girls study in this structure.

In Dakar

- Daara Abdoulay Ben Massoud in Dakar: Located in the popular district Parcelles-Assainies, this modern mixed daara has 200 students aged 5 to 15 years.

Inclusion criteria: children of both sexes aged 4 to 16 years who lived exclusively in the locality.

Exclusion criteria: subjects with congenital heart desease, valvular or other cardiac involvement that may explain pulmonary arterial hypertension; those who refused to adhere to the study protocol.

Study material:

The material used for our study is as follows:

- A branded "Listo PPE LL5" scale; a height; a LITTMAN-CLASSIC stethoscope, equipped with a double-headed receiver, a double-frequency membrane and a single tubing; an automatic arm blood pressure monitor "OMRON M3 V4";

- A "Fukuda Denshi Cardimax" electrocardiograph "fx-7202";

- A "Sonosite 180 Plus Portable Ultrasound System" Cardiac Ultrasound System with pulsed, continuous and color Doppler;

- A capillary hemoglobin reader, using the "HemoCue $\mathrm{Hb} 301$ " system: easy to use, by introducing a drop of blood, obtained by pricking the fingertip with a retractable, sterile and non-reusable lancet, and then introducing into a portable photometer indicating the level of hemoglobin by a properly validated analytical method [11]. 
Parameters studied:

- Examination: dyspnea, hemoptysis, hematuria.

- Physical examination: weight, height, breath, radiance of the second pulmonary sound.

- Biological examinations.

- In the urine: parasitological examination in research, in the urinary pellet, of Schistosoma hæmatobium. The samples were taken during the survey, the examination by a parasitologist, the results were not revealed until the data analysis.

○ In the blood: determination of the hemoglobin level.

- Electrocardiogram: it was analyzed by a cardiologist. We were interested in rhythm, in the existence of chambers hypertrophy.

- Doppler echocardiography: it allowed to measure cardiac chambers. The study focused on the right ones including the right ventricle: diameter in long axis longitudinal section, the basal and medial dimensions in apical cut four cavities. These dimensions were related to the body surface. The pulmonary arterial systolic pressure (sPAP) was assessed by the tricuspid regurgitation flow: the maximum gradient between the right ventricle and atrium was determined by the Bernoulli equation; the study of the inferior vena cava, which gave the value of the pressure of the right auricle; the pulmonary pressure was thus obtained by the sum of the two elements.

Data Collection and Survey Flow:

Data were collected on a survey sheet with two components:

- A section containing the civil status data previously filled by the children with the assistance of their parents and guardians and/or their teachers.

- A section containing data from the clinical examination, the cardiac echography, filled by the doctors.

Ethical and regulatory aspect:

This work was done in collaboration with the parasitology laboratory of the Cheikh Anta Diop University of Dakar. An information note has been prepared for the parents of students or legal guardians. The identity of the patients had been preserved and confidentiality respected.

Data entry and processing:

All observations were entered and coded on Windows Excel 2010 (Microsoft, USA) and analyzed using PASW Statistics 18 (IBM, Chicago, IL, USA). Excel software was used to present tables and graphs, as well as to group the terms of some variables before their analysis. Descriptive statistics presented the data in the form of tables and figures. It then summarized the qualitative variables as proportions (percentages) and quantitative variables as medians (Interquartiles). For qualitative variables, comparison of percentages required the Pearson chi-square test with Yates correction when necessary for small samples. The Wilcoxon-Mann-Withney U-test was used to compare asymmetric quantitative variables (distribution that does not follow Gauss-Laplace's normal distribution). 
The statistical inference required for the analytical study was used to study associations using statistical tests for the comparison of variables (logistic regression) and relative risk (RR) calculations with the 95\% confidence interval (95\% CI). A value of $\mathrm{p}<0.05$ was considered significant.

\section{Results}

- Characteristics of the population:

In total, we examined 251 children divided between the two regions. There was one child excluded because of the presence of significant mitral insufficiency in the latter. There were 250 children included in our study.

There were 161 and 89 children respectively included in Richard Toll and Dakar. There was male predominance: 40 girls (24.8\%) and 121 boys (75.2\%) to Richard Toll; 20 girls (22.5\%) and 69 boys (77.5\%) in Dakar.

The subjects were aged 4 to 16 years with an average of 10 years \pm 2.77 .

- Clinical data:

Hematuria was reported in $69.6 \%$ of the study population in endemic areas. No cases were reported in Dakar. There was no significant difference in heart rate and body mass index. A pulmonary accentuated second heart sound (S2) was noted in 49 subjects, exclusively in the Richard Toll subgroup. Table 1 summarizes the clinical data.

- Biology:

- Urine parasitological examination:

Positivity in Schistoma hæmatobium was excusively found at Richard-Toll. There were 54 subjects (33.5\%), including 52 boys ( $43 \%$ boys) and 2 girls (5\% girls).

- Hemoglogin:

The average hemoglobin level was $10.77 \pm 1.9 \mathrm{~g} / \mathrm{dL}$. It was $10.64 \pm 2.2 \mathrm{~g} / \mathrm{dL}$ at Richard-Toll, and $10.9 \pm 1.1 \mathrm{~g} / \mathrm{dL}$ at Dakar. In the Richard Toll subgroup, there was a statistically significant relationship between anemia and the positivity of parasitological examination $(\mathrm{p}=0.032)$. There was a link between anemia and dyspnea $(\mathrm{p}=0.045)$. There was no correlation between history of hematuria and anemia $(\mathrm{p}=0.897)$

- Electrocardiogram:

The rhythm was sinusal in all cases. On average, the axis of the heart was 56.4 \pm 3.3 : it was $55.9 \pm 3.2$ at Richard-Toll and $57.2 \pm 3.5$ at Dakar $(\mathrm{p}=0.610)$.

Right ventricular overload indices were similar for both populations, with the Lewis index being 2.0 \pm 0.2 at Richard-Toll and $1.9 \pm 0.2$ at Dakar $(\mathrm{p}=0.595)$.

In the Richard-Toll subgroup, left ventricular hypertrophy was noted in two children, a complete right bundle block in another child.

- Doppler echocardiography:

Left cavities:

The end diastolic, end systolic, basal and medial dimensions of the left ventricle were larger in Richard Toll's population compared to Dakar. The ratio to 
the body surface found a significant difference in basal diameter. Table 2 below summarizes the various data of the left ventricle.

The mean surface of the left atrium was $11.22 \pm 2.48 \mathrm{~cm}^{2}$. Reported to the body surface, it was $12.23 \pm 2.49 \mathrm{~cm}^{2}$ and $12.19 \pm 2.73 \mathrm{~cm}^{2}$, respectively, in the populations of Richard Toll and Dakar $(\mathrm{p}=0.989)$.

Right cavities:

The study of the right ventricle revealed a significantly greater right parasternallong axis diameter in the population of Richard Toll ( $\mathrm{p}<0.001)$. Table 3 summarizes the different right ventricular measurements recorded.

Right atrium surface was on average of $9.24 \pm 2.15 \mathrm{~cm}^{2}$ in the overall population. Among Richard-Toll's children, we found a value of $9.49 \pm 2 \mathrm{~cm}^{2}$, while its value was of $8.79 \pm 2.21 \mathrm{~cm}^{2}$ among children of Dakar $(\mathrm{p}=0.007)$. This difference remained significant when comparing the body surface area $(10.5 \pm 2.2$ $\mathrm{cm}^{2} / \mathrm{m}^{2}$ against $9.7 \pm 2.32 \mathrm{~cm}^{2} / \mathrm{m}^{2}$ with $\mathrm{p}=0.006$ ).

Table 1. Summary of clinical data.

\begin{tabular}{ccccc}
\hline & Overall population & Richard-Toll & Dakar & p \\
\hline Dyspnea & 45 & 44 & 1 & $<0.001$ \\
Hemoptysis & 7 & 7 & 0 & 0.046 \\
Hematuria & 112 & 112 & 0 & $<0.001$ \\
Heart rate & $92 \pm 16$ & $93 \pm 18$ & $90 \pm 12$ & 0.215 \\
BMI & $14.8 \pm 1.6$ & $14.8 \pm 1.8$ & $14.8 \pm 1.4$ & 0.675 \\
Body area & $0.9 \pm 0.17$ & $1 \pm 0.20$ & $0.9 \pm 0.15$ & 0.66 \\
Mitral systolic murmur & 12 & 12 & 0 & $<0.001$ \\
accentuated S2 & 49 & 49 & 0 & $<0.001$ \\
\hline
\end{tabular}

Table 2. Summary of cavitary dimensions of the left ventricle.

\begin{tabular}{|c|c|c|c|c|}
\hline & Overall population & Richard Toll & Dakar & $\mathrm{p}$ \\
\hline End diastolic LV (mm) & $38.2 \pm 4.68$ & $38.62 \pm 4.9$ & $37.43 \pm 3.9$ & 0.057 \\
\hline $\begin{array}{l}\text { End diastolic LV/body area } \\
\qquad\left(\mathrm{mm} / \mathrm{m}^{2}\right)\end{array}$ & $39.1 \pm 4.8$ & $39.63 \pm 5.1$ & $38.37 \pm 4.1$ & 0.045 \\
\hline End systolic LV (mm) & $22.6 \pm 3.72$ & $23.42 \pm 3.7$ & $21.3 \pm 3.2$ & $<0.001$ \\
\hline $\begin{array}{c}\text { End systolic } \mathrm{LV} / \text { Body surface } \\
\text { area }\left(\mathrm{mm} / \mathrm{m}^{2}\right)\end{array}$ & $23.3 \pm 3.9$ & $23.6 \pm 4.3$ & $22.8 \pm 3.0$ & 0.273 \\
\hline Median LV (mm) & $34.4 \pm 5.1$ & $35.08 \pm 5.2$ & $33.16 \pm 4.6$ & 0.002 \\
\hline $\begin{array}{c}\text { Median LV/body surface area } \\
\qquad\left(\mathrm{mm} / \mathrm{m}^{2}\right)\end{array}$ & $35.4 \pm 5.9$ & $40.3 \pm 6.43$ & $35.4 \pm 6.4$ & 0.8 \\
\hline Basal LV (mm) & $39.6 \pm 4.7$ & $40 \pm 4.9$ & $33.8 \pm 4.3$ & 0.035 \\
\hline $\begin{array}{l}\text { Basal LV/body surface area } \\
\qquad\left(\mathrm{mm} / \mathrm{m}^{2}\right)\end{array}$ & $40.7 \pm 6.65$ & $40.3 \pm 6.43$ & $41.3 \pm 7$ & 0.83 \\
\hline
\end{tabular}


Table 3. Summary of the right ventricular dimensions.

\begin{tabular}{|c|c|c|c|c|}
\hline Measures & Overall population & Richard Toll & Dakar & $\mathrm{p}$ \\
\hline RV pla (mm) & $17.34 \pm 2.3$ & $17.95 \pm 2.9$ & $16.23 \pm 2.8$ & $<0.001$ \\
\hline $\begin{array}{l}\text { RV pla/body surface area } \\
\qquad\left(\mathrm{mm} / \mathrm{m}^{2}\right)\end{array}$ & $17.82 \pm 3.2$ & $18.08 \pm 3.2$ & $17.57 \pm 3.3$ & $<0.001$ \\
\hline $\mathrm{RV} s \mathrm{~s}(\mathrm{~mm})$ & $19.46 \pm 2.6$ & $19.61 \pm 2.6$ & $18.82 \pm 2.3$ & $<0.001$ \\
\hline $\begin{array}{l}\text { RV sa/body surface area } \\
\qquad\left(\mathrm{mm} / \mathrm{m}^{2}\right)\end{array}$ & $20.18 \pm 3.2$ & $20.05 \pm 3.6$ & $20.32 \pm 3.1$ & 0.310 \\
\hline Basal RV (mm) & $33.6 \pm 4.3$ & $33.9 \pm 4.3$ & $33 \pm 4.21$ & 0.104 \\
\hline $\begin{array}{l}\text { Basal RV/body surface area } \\
\qquad\left(\mathrm{mm} / \mathrm{m}^{2}\right)\end{array}$ & $34.7 \pm 5.9$ & $34.39 \pm 6.3$ & $35.5 \pm 4.8$ & 0.208 \\
\hline Median RV (mm) & $28.42 \pm 4.0$ & $29.0 \pm 4.0$ & $27.35 \pm 4.0$ & 0.002 \\
\hline $\begin{array}{l}\text { Median RV/body surface area } \\
\qquad\left(\mathrm{mm} / \mathrm{m}^{2}\right)\end{array}$ & $29.3 \pm 5.21$ & $29.38 \pm 5.62$ & $29.4 \pm 4.4$ & 0.864 \\
\hline
\end{tabular}

pla $=$ parasternal long axis; $\mathrm{sa}=$ short-axis.

Pulmonary arterial data:

The average diameter of the pulmonary artery was of $18.29 \pm 2.8 \mathrm{~mm}$ in the overall population. It was significantly higher in the population of Richard Toll than that of Dakar: $19.18 \pm 2.74 \mathrm{~mm}$ and $16.69 \pm 2.24 \mathrm{~mm}$ respectively $(\mathrm{p}=$ 0.001).

The average diameter of the right pulmonary artery was of $9.74 \pm 1.6 \mathrm{~mm}$ in the overall population. This value at Richard Toll and Dakar was equal to $9.71 \pm$ $1.42 \mathrm{~mm}$ and $8.28 \pm 2.3 \mathrm{~mm}$ respectively.

The average diameter of the left pulmonary artery was of $9.74 \pm 1.6 \mathrm{~mm}$ in the overall population. This value at Richard Toll and Dakar was equal to $9.81 \pm 1.75$ $\mathrm{mm}$ and $9.62 \pm 3.2 \mathrm{~mm}$ respectively.

The average sPAP was higher in Richard-Toll: $26.38 \pm 3.16 \mathrm{mmHg}$ versus $21.82 \pm 1.73 \mathrm{mmHg}$ in Dakar $(\mathrm{p}<0.001)$. A systolic arterial pressure higher than $35 \mathrm{~mm} \mathrm{Hg}$ was noted on one individual (0.6\%) residing in Richard Toll. All sPAP measures were inferior to $25 \mathrm{~mm} \mathrm{Hg}$ in the population of Dakar, versus $60.2 \%(\mathrm{n}=97)$ of measures $>25 \mathrm{mmHg}$ in Richard Toll $(\mathrm{p}<0.001)$. In the latter effective population, 25 individuals (15.5\%) had a sPAP value superior or equal to $30 \mathrm{~mm} \mathrm{Hg}$. Several factors were statistically linked to the sPAP value in Richard Toll's population: presence of hematuria $(p<0.001)$, anaemia $(p<0.001)$ and positivity of parasitological examination $(\mathrm{p}<0.0001)$. There was no correlation between the sPAP value and the right ventricle dimensions $(\mathrm{p}=0.2)$.

The pericardium was normal in both populations.

\section{Discussion}

Schistosomiasis is a very old affection. Indeed, ancient Egypt is considered the original home of the two main species found in Africa: $S$. hæmatobium and $S$. mansoni [12]. Hieroglyphs probably representing the main symptom of schisto- 
somiasis (then called "aaa" disease), were found on papyrus dating from 1500 to 1900 years before our era. Calcified $S$. hæmatobium eggs have been found in the bladder of embalmed mummies [13].

In 2015, WHO defined a state of endemic Schistosomiasis in 78 countries [1]. Africa is the continent most affected. Around the world in 2012, 5 countries had a prevalence above 50\%, all of which are in Africa: Tanzania, Mozambique, Ghana, Madagascar and Sierra Leone [14]. The country with the highest number of infected people in Africa is Nigeria (29 million people infected) [15].

School-age children (aged 5 -14) are one of the groups most at risk of being infected with schistosomiasis. This is due in particular to lack of hygiene and play in the water [16]. Children play mainly in shallow waters at high temperatures, places where intermediate hosts are preferentially located. the boys were the most affected, this predominance is related to the lower education of girls, especially in the Daaras. In some areas, the prevalence of urinary schistosomiasis among school-aged children can reach 80\% [17].

Several complications of Schistosomiasis have been described. In addition to $\mathrm{PH}$, cases of myocardial and pericardial involvement have been reported [6] [7] [8]. Clinical manifestations as well as complications depend on the species but also on the stage and duration of infestation [4]. It is described that the Mansoniform, with digestive tropism, is rather responsible for PH [18] [19]. This complication constitutes the most known cardio-vascular disease of Schistosomiasis. Research in Brazil on the prevalence of pulmonary hypertension in bilharzeal subjects showed that of 246 patients with echocardiographic signs of $\mathrm{PH}, 80 \%$ were bilharzial [18].

We found only the hæmatobium form in Richard Toll's population. This form of urinary tropism is responsible for hematuria. Moreover, this symptom was reported in $69.6 \%$ in this subgroup. Pulmonary signs, including calcified nodules, have been reported in patients with this form of bilharziasis [20]. This is easily understood since the development cycle of the disease involves a pulmonary phase.

The pathophysiology of Schistosomiasis associated $\mathrm{PH}$ remains highly debated: between embolic mechanism, angiogenesis but also and especially inflammation. There appears to be two ages of onset of this complication following the course of the disease. This is the young age: the acute infection is responsible for massive embolization of parasitic eggs. It is then the older subjects, carriers of chronic forms associating a cascade of auto-immune inflammation and a portal hypertension which is specific to the schistosomiasis to Mansoni species [18].

Recent data indicate a smaller share of parasite egg emboli in the pathophysiology of this HTAP. In fact, in autopsy data, the authors reported the small number or absence of eggs or egg antigens at the pulmonary autopsy of Schistosomiasis associated PH patients. They retained inflammation and portal hypertension as the main physiopathological hypotheses that are more specific to the 
Mansoni form [21]. More specifically, the role of TGF- $\beta$ in Schistosomiasis associated $\mathrm{PH}$ has been described. Its activation would be mediated by Th2 cytokines IL4 and IL13 [22].

In our population, we found just one sPAP greater than $35 \mathrm{mmHg}$. However, the sPAP value was significantly greater in the endemic area. The physiopathological data described above could explain this fact. This is a young population, in acute phase of infection. The increase in sPAP could be explained, in part, by the embolization of parasitic eggs in the pulmonary vascular tree. In addition, we found larger pulmonary arterial dimensions in the endemic area.

There are other possible attacks of bilharziasis. This is for example endomyocardial fibrosis that has been reported in Egypt in a proportion of 15/10000 infected persons. However, this ratio was not confirmed by Brazilian data [18] [23].

Cavity diameters were found to be larger in the endemic area. Anemia may play a role in increasing cavitary dimensions. It has been shown that hemoglobin levels are associated with increased diameters of the heart chambers. Similarly, its correction leads to a normalization of these dimensions [24]. It is a coping mechanism that involves an increase in cardiac index and ejection volume [25]. Pathophysiologically, increased sympathetic and inotropic activity as well as additional myocardial stress may explain myocyte and vascular remodeling. There is a decrease in myocardial oxygen consumption despite an increase in workload and oxygen extraction [26]. Anemia also causes dilatation of the left atrium due to diastolic dysfunction [27].

\section{Conclusion}

Our work performed in the endemic area of bilharziasis with $S$. hæmatobium shows a significant frequency of hematuria and dyspnea. The heart of the school-aged child is characterized by larger cavitary dimensions. Similarly, the values of systolic pulmonary arterial pressures are significantly greater even if the threshold defining $\mathrm{PH}$ is rarely exceeded. The hypotheses of these cardiovascular modifications are anemia but also acute bilharzeal infection with a massive pulmonary embolism of eggs as part of the cycle of the disease.

\section{Conflicts of Interest}

The authors declare that they have no conflict of interest.

\section{Acknowledgements}

We thank the daara officials, the parasitology laboratory, doctors of the Richard Toll region.

\section{References}

[1] World Health Organization (2013) Relevé épidémiologique hebdomadaire. http://www.who.int/wer/2013/wer8808.pdf 
[2] Colley, D.G., Bustinduy, A.L., Secor, W.E., et al. (2014) Human Schistosomiasis. The Lancet, 383, 2253-2264. https://doi.org/10.1016/S0140-6736(13)61949-2

[3] Ministère sénegalais de la santé et de l'action sociale. Plan directeur de lutte intégrée contre les maladies tropicales négligées, 2011-2015.

https://www.ntdenvision.org/sites/default/files/docs/1206_senegal_plan_directeur_ mtn.pdf

[4] Ross, A.G., Bartley, P.B., Sleigh, A.C., et al. (2002) Schistosomiasis. The New England Journal of Medicine, 346, 1212-1220. https://doi.org/10.1056/NEJMra012396

[5] Hoette, S., Figueiredo, C., Dias, B., et al. (2015) Pulmonary Artery Enlargement in Schistosomiasis Associated Pulmonary Arterial Hypertension. BMC Pulmonary Medicine, 15, 118. https://doi.org/10.1186/s12890-015-0115-y

[6] Sarazin, M., Caumes, E., Cohen, A., et al. (2004) Multiple Microembolic Borderzone brain Infarctions and Endomyocardial Fibrosis in Idiopathic Hypereosinophilic Syndrome and in Schistosoma Mansoni Infestation. Journal of Neurology, Neurosurgery, and Psychiatry, 75, 305-307.

[7] De Jesus, A.R., Silva, A., Santana, L.B., et al. (2002) Clinical and Immunologic Evaluation of 31 Patients with Acute Schistosomiasis Mansoni. The Journal of Infectious Diseases, 185, 98-105. https://doi.org/10.1086/324668

[8] Chisty, M.M., Nargis, M., Sato, H., et al. (1999) Occurrence of Myocarditis in Rodents Infected with Schistosoma Mansoni. The Southeast Asian Journal of Tropical Medicine and Public Health, 30, 556-561.

[9] Gaye, O., Diallo, S., Ndir, O., et al. (1991) Bilharziose intéstinale dans la commune de Richard-Toll. Médecine d'Afrique Noire, 38, 3 p.

[10] Diop, P.S. (2010) Daara. In: Glossaire du roman sénégalais, L’Harmattan, Paris, 134-135.

[11] Cohen, A.R. and Seidl-Friedman, J. (1988) HemoCue System for Hemoglobin Measurement. Evaluation in Anemic and Nonanemic Children. American Journal of Clinical Pathology, 90, 302-305. https://doi.org/10.1093/ajcp/90.3.302

[12] Nozais, J.-P., Datry, A. and Danis, M. (1996) Traité de parasitologie médicale. Pradel, Paris, 817 p.

[13] Ripert, C. (2005) Epidémiologie des maladies parasitaires 2 in Helminthoses. Tec \& Doc Lavoisier, Cachan, 562 p.

[14] Institut de Veille Sanitaire. Epidémiologie de la bilharziose. http://www.invs.sante.fr/Dossiers-thematiques/Maladies-infectieuses/Maladies-a-tr ansmission-vectorielle/Bilharziose/Epidemiologie-de-la-bilharziose

[15] Adenowo, A.F., Oyinloye, B.E., Ogunyinka, B.I., et al. (2015) Impact of Human Schistosomiasis in Sub-Saharan Africa. Brazilian Journal of Infectious Diseases, 19, $10 \mathrm{p}$.

[16] World Health Organization (2013) Schistosomiase (Bilharziose): Aide-Mémoire. No. 115.

[17] Wikman-Jorgensen, P.E., Henríquez-Camacho, C.A., Serrano Villar, S., et al. (2012) The Role of Artesunate for the Treatment of Urinary Schistosomiasis in Schoolchildren: A Systematic Review and Meta-Analysis. Pathogens and Global Health, 106, 397-404. https://doi.org/10.1179/2047773212Y.0000000038

[18] Barbosa, M.M., Lamounier, J.A., Oliveira, E.C., et al. (1996) Pulmonary Hypertension in Schistosomiasis Mansoni. Transactions of the Royal Society of Tropical Medicine and Hygiene, 9, 663-665. https://doi.org/10.1016/S0035-9203(96)90424-1

[19] Lambertucci, J.R., Carvalho, V.T. and Silva, L.C. (2006) Pulmonary Hypertension in 
Schistosomiasis Mansoni. Revista da Sociedade Brasileira de Medicina Tropical, 39, 295-296. https://doi.org/10.1590/S0037-86822006000300016

[20] Gobbi, F., Buonfrate, D., Angheben, A., et al. (2017) Pulmonary Nodules in African Migrants Caused by Chronic Schistosomiasis Federico. The Lancet Infectious Diseases, 17, 159-165. https://doi.org/10.1016/S1473-3099(16)30530-8

[21] Safdar, Z., Bartolome, S. and Sussman, N. (2012) Portopulmonary Hypertension: An Update. Liver Transplantation, 18, 881-891. https://doi.org/10.1002/lt.23485

[22] Graham, B.B., Bandeira, A.P., Morrell, N.W., et al. (2010) Schistosomiasis-Associated Pulmonary Hypertension: Pulmonary Vascular Disease: The Global Perspective. Chest, 137, 20S-29S. https://doi.org/10.1378/chest.10-0048

[23] Rashwan, M.A., Ayman, M., Ashour, S., et al. (1995) Endomyocardial Fibrosis in Egypt: An Illustrated Review. Heart, 73, 284-289. https://doi.org/10.1136/hrt.73.3.284

[24] Cho, J., Mun, Y.C., Kwon, K.H., et al. (2014) Effect of Anemia Correction on Left Ventricular Structure and Filling Pressure in Anemic Patients without Overt Heart Disease. The Korean Journal of Internal Medicine, 29, 445-453. https://doi.org/10.3904/kjim.2014.29.4.445

[25] Metivier, F., Marchais, S.J., Guerin, A.P., et al. (2000) Pathophysiology of Anaemia: Focus on the Heart and Blood Vessels. Nephrology Dialysis Transplantation, 15, 14-18. https://doi.org/10.1093/oxfordjournals.ndt.a027970

[26] Bahl, V.K., Malhotra, O.P., Kumar, D., et al. (1992) Noninvasive Assessment of Systolic and Diastolic Left Ventricular Function in Patients with Chronic Severe Anemia: A Combined M-Mode, Two-Dimensional, and Doppler Echocardiographic Study. American Heart Journal, 124, 1516-1523. https://doi.org/10.1016/0002-8703(92)90066-5

[27] Lester, S.J., Tajik, A.J., Nishimura, R.A., et al. (2008) Unlocking the Mysteries of Diastolic Function: Deciphering the Rosetta Stone 10 Years Later. Journal of the American College of Cardiology, 51, 679-689. https://doi.org/10.1016/j.jacc.2007.09.061 